\title{
MATRIMONIO Y FAMILIA: \\ INFORMACION SOBRE EL PARENTESCO
}

Roger Rodriguez Iturri

\section{INTRODUCCION}

Este trabajo intenta presentar noticias sobre el parentesco familiar.

Un estudio sobre el parentesco, no puede estar desligado de sus fuentes típicas: el matrimonio (en su diversidad de formas históricas y culturales), y de la familia (según sus tipos y concepciones en los diversos lugares y a través del tiempo).

Por eso el presente trabajo tiene necesariamente que combinar información entre estas tres instituciones sociales (matrimonio, familia y parentesco).

Enneccerus y Engels, entre otros, sostienen que la historia de la familia es la historia de su descomposición, en grupos más pequeños. En efecto, los datos de la historia de la cultura nos conducen a refrendar esta afirmación.

Para ello en este trabajo, nos hemos visto precisados a conjugar datos antropológicos, históricos, sociales, culturales y jurídicos, en un intento de escudriñar en la intrincada maraña que significa el estudio retrospectivo, y aún actual, de la familia y el parentesco.

Asistiéndonos de los clásicos en antropología familiar, recogiendo fuentes modernas y clásicas en el aspecto histórico, hemos arribado al concepto jurídico actual sobre el parentesco en la familia occidental peruana.

El trabajo revela la sustantiva distancia existente entre el concepto actual de familia occidental, y las diversas concepciones y contenido cultural de ella a través de la historia. 


\section{ANTROPOLOGIA FAMILIAR, ALGUNAS NOTICIAS}

Los estudiosos de la materia sostienen que hasta 1860 no era fácil encontrar un texto sobre la historia de la familia.

La influencia del Antiguo Testamento había marcado un carácter patriarcal en ésta. Había quedado admitido un cierto origen de la familia en promiscuidad sexual, la vigencia de la poligamia, de la poliandría y la presencia de la monogamia; se percibieron los signos de cierto tipo familiar materno y de uniones matrimoniales por grupos; pero estas formas no podían entonces ser ordenadas históricamente de modo sucesivo. Taylor, en "Investigaciones de la Historia Primitiva de la Humanidad", las llamó “costumbres raras".

En rigor parece que el estudio de la historia de la familia comienza con Bachofen y su "Derecho materno", escrito en 1861. Bachofen sostuvo que los hombres primitivos vivieron en promiscuidad sexual; que ello imposibilitaba la certeza de la paternidad; y que por tanto las madres consideradas progenitores, gozaban de gran aprecio y respeto; sólo después - dice- aparecería la monogamia, que encerraba la trasgresión de una antiquísima ley religiosa, trasgresión que debía ser castigada o cuya tolerancia se resarcía con la posesión de la mujer por otros durante determinado período. Bachofen penetra de religiosidad su concepto de mutación familiar.

Sucesor en estas investigaciones es el trabajo de MacLennan, "Estudios de Historia Antigua", del año 1886.

MacLennan encontró en muchos pueblos antiguos y modernos una forma de matrimonio por la que el novio, solo o con amigos, rapta con violencia simulada a la futura esposa.

Encontró también pueblos no civilizados dentro de los cuales estaba prohibido el matrimonio, obligándose los hombres a buscar esposas y las mujeres esposos fuera del grupo; en tanto en otros existió una costumbre por la que los hombres sólo podían tomar mujeres de su propia unidad. Las primeras son, para MacLennan, "tribus exógamas"; las segundas, "tribus endógamas". 
La causa de esta costumbre - dice MacLennan- podría hallarse en la tradición muy difundida entre los salvajes de matar a las niñas que nacen, por lo que resultaría un excedente de hombres en cada tribu que tendrían en común una misma mujer, dentro de un sistema poliándrico. En virtud de ello se sabría quién era la madre de un niño, pero no quién era el padre. Por eso la ascendencia sólo se contaba en línea materna y no paterna. La escasez de mujeres en la tribu, sería precisamente la causa del rapto sistemático de mujeres de tribus extrañas.

Empero mientras MacLennan sólo reconocía tres formas matrimoniales, la poligamia $(*)$, la poliandría y la monogamia, se hallaban pruebas, cada vez más numerosas, en el sentido de que en otras tribus existían matrimonios en los que varios hombres tenian en común varias mujeres. Lúbbok en "El Origen de la Civilización" en 1870, denominó a esta relación matrimonio por grupos, concepto enriquecido mucho por el misionero inglés Lorimer Fison.

Entre tanto, en 1871, Morgan radicado entre los nativos iroqueses, se convencía de que su sistema de parentesco, era común a todos los aborigenes de los Estados Unidos.

A partir de sus comprobaciones, el investigador norteamericano dedujo que:

- el sistema de parentesco de las indias americanas estaba en vigor en Asia, y ligeramente modificado en tribus de Africa y Australia;

- que tal sistema tenía su más completa expresión en una forma matrimonial por grupos en proceso de extinción en Hawai y otras islas de Australia;

(*) En torno a la discutida poligamia, su origen parece refundirse con el de la esclavitud. La poligamia tiende a limitarse a gentes de posición elevada. En la familia patriarcal semítica, el líder y su círculo de varones viven como polígamos; a los otros se les impone la monogamia. Los estudios en Oriente nos dicen que la poligamia coincide con el privilegio de los ricos y de los grandes; la masa del pueblo es monógama. 
- y que en estas mismas islas, junto a esa forma de matrimonio, existia un sistema de parentesco que sólo podía explicarse mediante un tipo, desaparecido hoy, de matrimonios por grupos más primitivos aún.

Afirmó también que en la época en que aún dominaba el matrimonio por grupos, la tribu se escindió en cierto número de grupos, de gens consanguíneos por línea materna, dentro de los cuales estaba prohibido el matrimonio, por lo que los hombres tomaban mujeres de otras gens, sin perjuicio de poseer algunas de su propia unidad.

Descubrió luego que la gens, organizada según el derecho materno, fue la fuente primitiva de la gens posterior basada en el derecho paterno, la que fue hallada en los pueblos civilizados de la antiguiedad.

Dentro de las grandes investigaciones científicas y sociales, la Escuela Clásica, afirma que la primera etapa de interrelación privada del hombre, la del "vagus concubitus", estuvo marcada por un hetairismo tal que, hombre y mujer satisfacian sus apetencias sexuales, sin que exista conciencia alguna de la vinculación entre cohabitación, fornicación y parto.

La "voubeergende paarung" de Eleuterópulos, tampoco constituyó familia a nuestro estilo. El padre quedó excluido de la relación práctico-filial, en tanto que la relación madre-hijo sólo operó hasta el destete.

La teoría evolucionista clásica afirma que fue el matriarcado el tercer momento. La ginecocracia (autoridad de la mujer), aparejada al poliandrismo, fueron las características de esta etapa. Sólo después habría aparecido, se dice, la huella de la familia patriarcal y con tendencia monogámica, como se apreció en las tribus bárbaras y en los pueblos de Oriente.

Sin embargo todo lo dicho, no es sino una manera de concebir el proceso y génesis de la familia en la historia. La teoría evolucionista moderna, se encarga de presentarnos otro proceso, distinto, en el que luego de la "voubeergende paarung", tuvieron 
cabida la familia consanguínea (relaciones sexuales entre familiares), la punalúa (en la que se prohíbe la unión de sexos entre parientes), y la sindiásmica (un hombre opta por una favorita, sin perjuicio de tener varias mujeres), para arribar luego a formas matriarcales y patriarcales.

Todo ello, sin embargo, se contrapone con el análisis que la Escuela Histórico-Cultural, ha hecho en el mundo respecto a la familia. Sostiene el origen monogámico y patriarcal de la familia; pero admite que la firmeza del patriarcalismo perdió solidez en la historia, a través de las fórmulas nucleares de la "sociedad familiar inestable" y la "familia estirpe", en la que la implicancia económica no deja de tener efecto familiar, para concluir tal proceso en fórmulas parentales de gobierno matriarcal.

En verdad parece que la cultura ha impuesto a través del tiempo formas de matrimonio, familia y parentesco muchas veces intrincadas y disímiles.

Por ejemplo, en Egipto, se afirma que la familia fue patriarcal; en Caldea la maldición de la madre sirvió para excluir al hijo de la familia; la adopción en Asiria antecedió en vigencia a Grecia y Roma; entre los hindúes, se sostiene que, la familia fue patriarcal, con evidencias, según el Mahababarata, de promiscuidad sexual. Preceptúa éste que “. . . las mujeres son comunes. . . hubo un tiempo en el que ser infiel a la mujer por el esposo, no era delito sino deber. ..". Entre los hindúes los abuelos pertenecen a la familia anterior, y la ley de la viudedad obligaba a la esposa modelo a incinerarse viva en el mismo fuego destinado al cadáver del marido. El Código de Manú descansa en la filiación masculina y en el patriarcado. Entre los chinos los hijos de todas sus mujeres se reputaban de la primera, con calidad de hijos legítimos; el patriarcado y la poligamia fueron signos del matrimonio, la familia y el parentesco en el antiguo Israel; entre los griegos se admitió como hijos legítimos los de la mujer legítima, los demás aún los provenientes de las concubinas eran ilegítimos. Empero, el padre podía legitimar a los hijos y; en fin, se pueden añadir sinnúmero de formas y relaciones para el matrimonio, la familia y el parentesco, antes de que se produzca el arribo histórico y social a la forma monogámica. 
Bachofen sostuvo que ella fue conquista de las mujeres. Apunta que paulatinamente la mujer percibió con más conciencia su situación casi envilecida y oprimida. Debió anhelar, con mayor fuerza, como liberación, el derecho a la castidad, y al matrimonio temporal o definitivo con un solo hombre. Aunque esta conquista no esté aislada de otros factores sociales y económicos.

De otro lado, pero sobre tal materia, Engels en "El Origen de la Familia, Propiedad Privada y Estado", en 1885, sostenía que por naturaleza el amor sexual es exclusivista, y que el matrimonio fundado en el amor sexual es, por su propia naturaleza, monógamo (*). Empero ello no es óbice para que él denuncie los perfiles que aprecia en la monogamia.

Engels sostiene que la monogamia "se funda en el predominio del hombre; su fin expreso es el de procrear hijos cuya paternidad sea indiscutible; $y$ esta paternidad indiscutible se exige porque los hijos, en calidad de herederos directos, han de entrar un día en posesión de los bienes de su padre. La familia monogámica se diferencia del matrimonio sindiásmico por una solidez mucho más grande de los lazos conyugales, que ya no pueden ser disueltos por deseo de cualquiera de las partes. Ahora, sólo el hombre, como regla, puede romper estos lazos y repudiar a su mujer. También se le otorga el derecho de infidelidad conyugal, sancionado, al menos, por la costumbre (el Código de Napoleón se lo concede expresamente, mientras no tenga la concubina en el domicilio conyugal), y este derecho se ejerce cada vez más ampliamente, a medida que progresa la evolución social. Si la mujer se acuerda de las antiguas prácticas sexuales y quiere renovarlas, es castigada más rigurosamente que en ninguna época anterior".

A nuestro juicio, va resultando incuestionable, el protagonismo de la cultura en la construcción de los tipos de matrimonio, familia y parentesco.

Aunque Westermark en "Historia del Matrimonio en la Espe-

(*) Contrario al matrimonio, Engels desde 1843, entabla relación amorosa con Mary Burns, con la que convive, así como con la hermana menor de ésta, Lizzy. 
cie Humana", haya sostenido que "tal vez no hubo etapa del desarrollo humano en que no haya existido el matrimonio", es evidente, de acuerdo a Morgan, que no se puede hablar en la historia de un solo concepto de matrimonio, familia y parentesco.

Hoy mismo, en igual tiempo y espacio geográfico, en el Africa, encontramos que mientras las organizaciones tribales de los merina, kikuya, vezo, bushmen, xhosa, amhara y haus, son grupos monógamos con parentesco bilateral; los anlo son coetáneamente monógamos y polígamos con parentesco patrilineal; en tanto los pigmeos (binga) practican la monogamia y consideran a todos los miembros del grupo como familia; los zulú; masay, shilluk y yoruba ejercen la poligamia en algunos casos con parentesco patrilineal y en otro con organización en clanes; la monogamia con parentesco bilateral y organización en clanes es práctica común entre los fulani de la misma Africa.

Es pues importante rescatar inmortales apareciaciones de Morgan ("La Sociedad Antigua"), a quien un siglo después el maestro en antropología familiar Claudio Lévi Strauss, dedica "Estructuras Elementales del Parentesco":

"La familia -dice Morgan- es el elemento activo; "nunca permanece estacionada, sino que pasa de una "forma inferior a una forma superior a medida que la "sociedad evoluciona de un grado más bajo a otro "más alto. Los sistemas de parentesco, por el contra"rio, son pasivos; sólo después de largos intervalos re"gistran los progresos hechos por la familia y no su"fren una modificación radical sino cuando se ha mo"dificado radicalmente la familia.

Y añade el antropólogo norteamericano:

"Si se reconoce el hecho de que la familia ha atravesa"do sucesivamente por cuatro formas y se encuentra "en la quinta actualmente, plantéase la cuestión de "saber si esta forma puede ser duradera en el futuro. "Lo único que puede responderse es que debe progresar a medida que progrese la sociedad, que debe modi- 
"ficarse a medida que la sociedad se modifique: lo "mismo que ha sucedido antes. Es producto del siste"ma social y reflejará su estado de cultura. Habiéndo"se mejorado la familia monogámica desde los comien"zos de la civilización, y de una manera muy notable

"en los tiempos modernos, lícito es, por lo menos, su"ponerla capaz de seguir perfeccionándose hasta que "se llegue a la igualdad entre los dos sexos. Si en un "porvenir lejano, la familia monogámica no llegase a "satisfacer las exigencias de la sociedad, es imposible "predecir de qué naturaleza sería la que le sucediese.

\section{SIGNOS DEL PARENTESCO ANDINO}

Es bastante difícil elaborar con realismo los rasgos del parentesco andino. Dificultades en las fuentes y en el lenguaje tornan complicado el análisis. Empero son varios los investigadores que han intentado enfrentar el asunto.

El profesor Zuidema, antropólogo de la Universidad de Illinois, ha realizado muy valiosos trabajos de campo en las comunidades andinas del Perú. Ha enfrentado el problema idiomático; y sin abandonar las fuentes históricas más conocidas, ha hurgado en diccionarios, registros parroquiales y estudios de autores que lo antecedieron.

De su importante y muy complicado trabajo intentamos extraer algunas conclusiones respecto al parentesco. Tales conclusiones no mantienen necesariamente un orden y pueden no resultar coordinadas entre sí, pero reflejan un conjunto informativo importante sobre el parentesco andino.

Veamos.

El grupo corporado andino se basaba en los conceptos de jerarquía y localidad; lo componían dos líneas de descendencia masculina y femenina; éstas constaban a su vez, de cuatro generaciones descendientes de un hombre.

El ayllu, según Kauffman, era una comunidad compuesta de 
varias familias. Empero, afirma Zuidema, el ayllu local no implicó en absoluto que la estructura interna de éste se construya en base a lazos reales de parentesco, sino tan sólo que tenga una delimitación. La importancia de este grupo, en términos de parentesco, es que se hace en él una distinción entre matrimonios de grupo y aquellos otros matrimonios que se realizan fuera de él.

Es importante conocer que, en el ayllu en estricto, se incluyen parientes hasta el cuarto grado; y que la regla social de contar cuatro generaciones en el modelo de ayllu, fue reconocida en las prohibiciones andinas del incesto.

Huamán Poma sostiene que los descendientes de un antepasado hasta los bisnietos no podían casarse entre sí; sólo podían hacerlo a partir del grado de tataranieto. Esto lo afirma también Garcilaso de la Vega cuando dice (Libro IV, Capítulo X) que sólo la nobleza podía casarse entre parientes hasta el cuarto grado.

En el caso de los incas, la terminología de parentesco, estaba íntimamente entrelazada con todos los aspectos de su organización social y religiosa, heredada de otras civilizaciones arcaicas del Perú, y que aparentemente no ostenta mayor influencia externa.

Aunque es difícil consignar en este trabajo todas las formas posibles de matrimonios para el inca, Zuidema llega a establecer en su estudio hasta seis probabilidades. Pero sobre el matrimonio, Huaman Poma sostiene la siguiente idea:

"Si una mujer de la clase alta indígena se casaba con "un hombre de la clase baja, adquiría la clase social "de este último; y si se casaba con un negro (raza des"preciada por Huamán Poma) se volvía negra. Sin em"bargo, si se casaba con un español, o sea, alguien de "clase más alta, no adquiría la clase social de este úl"timo, sino que se volvía una mestiza, igual que sus "hijos. Recibía entonces el rango de sus hijos y den"tro del sistema de parentesco quechua, se convertía "en la "hija" de su esposo. En contraste, al casarse "con un hombre de clase social más baja, éste no se "convertía en "hijo" suyo y por lo tanto ella no po- 
"día ser fundadora de ningún ayllu que incluyera a "su esposo. Estos datos confirman una de nuestras "primeras conclusiones: un ayllu o panaca sólo podía "tener un antepasado masculino. Ambos puntos en"fatizan otro hecho: después del matrimonio, la espo-

"sa se convertía en la "hija" del esposo: . . .

En materia de filiación y nobleza, Zuidema consigna que:

"Lo que sigue explicará cómo los auquicuna, dentro "de la clase de "hijos" legítimos, eran divididos en "hijos, nietos y bisnietos, o sea los tres rangos de la "nobleza. Toda la nobleza era reclasificada por rnedio "de términos de parentesco de descendencia en rela"ción con el nuevo rey, cuando éste era elegido. Esto "no tenía sólo fines utilitarios para el rey, sino que "era también necesario para todo el sistema de paren"tesco. En ese momento el rey se casaba con su her"mana de padre y madre y, como ya hemos explica"do, no sucedía a su padre en calidad de hijo (piorque "si así fuera los demás hijos continuarían tarnbién "siendo "hijos"), sino que lo reemplazaba desde el "centro del universo del parentesco, relegando a su "padre a la posición de un antepasado muerto. Pode"mos entender ahora que el término auqui, no es usa"do sólo para referirse únicamente al príncipe real, al "hijo de un rey, sino que también significa "ancestro" "(en aymara quiere decir "padre"). Advertimos tam"bién que aún un hermano podía referirse a su herma"no menor con el término de "padre", si es que este "último era rey y/o el jefe de la familia. El caso pare"ce ser similar al dado anteriormente, donde la gente "declaraba las momias de sus ancestros. Estos, de he"cho, incluirían a sus descendientes muertos.

En materia de ascendientes, parece que los incas usaron el término abuelo como un título de nobleza entre la gente no inca.

Interesante resulta consignar la vinculación entre el parentesco y el orden administrativo inca. Huamán Poma presenta en di- 
versos lugares de su crónica, la organización jerárquica social por la que a cada cargo administrativo corresponde un rasgo de parentesco en relación con el rey. Santa Cruz Pachacuti describe de similar manera la organización jerárquica del ejército inca.

De otro lado, Basadre sostiene que el estado inca dió importancia decisiva, dentro del ayllu, a la familia, cuyo número cumplía una función social y económica.

Para la antigua historia de la familia indígena peruana, Max Uhle, Latcham y Bandelier, exhiben pruebas importantes respecto a la existencia de una era matriarcal, interrumpida por el patriarcalismo inca. Sarmiento de Gamboa habló de la importancia de Mama Huaco, una de las hermanas de Manco Cápac, presentándola como feroz guerrera; y Huamán Poma consideró a Mama Huaco la auténtica fundadora del imperio de los incas.

Pero el patriarcalismo obtuvo finalmente vigencia histórica en el imperio. Cobo dirá:

"Y entre esta gente era tan sujetas las mujeres y tan "hechas al servicio de sus maridos y a seguir su vo"luntad, que, aunque fuesen muchas, no habían dife"rencias ni usaban más de lo que se les mandaba,

pero añade el cronista:

"No sólo servían (las mujeres) en los oficios caseros, "sino también en el campo; en las labranzas, semen"teras y beneficios de sus chácaras o heredades, en "edificar sus casas y llevar cargas, cuando sus maridos "caminaban, en paz y en guerra".

CONCEPTO FAMILIAR HISPANO

Un concepto distinto de familia llega desde Europa a América.

La Iglesia marcará con su propio sello el predominio y la vigencia de un determinado tipo familiar. 
El gran proceso desde los primeros siglos de la era cristiana, en que la Iglesia tolera las formas concubinarias de unión marital, concluirá finalmente con el tipo y forma matrimonial declarado en el Concilio de Trento (1545 a 1563).

El Decreto Tametsi estableció la forma para contraer solemnemente el matrimonio prescrito ya en el IV Concilio de Letrán, reunido bajo Inocencio III, y declaró, para el futuro inválidos los matrimonios clandestinos, que hasta ahora eran sólo ilícitos. Agregó que el matrimonio católico era uno, natural e indisoluble.

De otro lado, en el ordenamiento legal hispano, en materia matrimonial, las VII Partidas de Alfonso el Sabio (1256 a 1263), influenciadas por el modelo matrimonial católico, declaraba que el matrimonio es "el ayuntamiento de marido e mujer, fecho con tal entención de convivir siempre en uno e de non se departir, guardándole lealtad cada uno de ellos al otro y non se ayuntar el varón a otra mujer, ni ella otro varón, viviendo ambos a dos".

$\mathrm{Y}$ es que el matrimonio, para las leyes hispanas era, a la vez, el contrato romano de las justas nupcias y el sacramento de la Iglesia.

Fue el derecho de Castilla el que gobernó jurídicamente en las Indias, inspirado en el derecho romano, canónico, germano, y con rasgos menores de procedencia judía y árabe.

Todo el sistema quedó volcado en América, principalmente mediante:

a) El Derecho Romano hasta el S. VI.

b) El Fuero Juzgo en el S. VII (Derecho Germánico)

c) Los Fueros Particulares (de León 1020, de Nájera, 1076, de Sepúlveda, de Cuenca y de muchos otros) llamados también municipales.

d) El Fuero de los Fijosdalgo, dado en Nájera en 1138.

e) El Fuero Viejo de Castilla de 1212, reformado en 1256. 
g) Aparecen las complicaciones con el "Setenario" de Fernando el Santo que no ha llegado a nosotros, el "Especulo" de Alfonso $\mathrm{X}$ el Sabio, etc.

h) El Fuero Real de 1254 también de Alfonso X el Sabio, que fue un Código Municipal de aplicación general.

i) Las VII Partidas de Alfonso X, hechas desde 1256 a 1263.

j) El Ordenamiento de Alcalá y el Ordenamiento de Montalvo (1848) estableciendo las prelaciones de las leyes anteriores.

k) Las leyes de Toro de 1302 .

1) La Nueva Recopilación de 1567 mandada hacer por el Rey Felipe, llamada así con relación a la de Montalvo.

m) La Novísima Recopilación escrita por don Juan de la Reguera y Valdelomar, aceptada por Carlos IV y publicada en 1805, que es la de la mayor importancia para nuestro derecho, y cuya fuerza legal es superior a todas las demás.

Con la aparición de la legislación foral no sólo se propugnará y protegerá el matrimonio, sino que se incita directamente a él. Así, se señalan asignaciones a los casados, y se les conceden beneficios, honras, acciones y excepciones; se restringen los derechos de los solteros y se condena con toda severidad el divorcio.

En Burgos los solteros no podrán testimoniar;en Alcalá, Córdova y Molina la herencia será privilegio de los casados, con mujeres e hijos. En Salamanca y Logroño no guerrearán los casados con mujer enferma. Empero la legislación de Castilla y Aragón, por ser de raigambre germana, admite la herencia de los hijos naturales, sin más limitación "que no fueran engendrados en adulterio".

Los fueros eran no sólo enérgicos, sino terribles, con las mujeres de vida licenciosa. La ley foral de Cuenca, señala pena de muerte; la de Cáceres, horca para el explotador y muerte para ella; el Fuero Juzgo, más humanizado, desciende a trescientos azotes para las mujeres de vida desarreglada. 
Diversos datos históricos expresan el celo por cautelar en lo posible, el tipo de unión monogámica y fiel, dentro del concepto de familia para Indias.

Así, este tipo de familia se convierte en el oficial de América, sin que ello signifique que, paralelamente con él, no supervivan los modos y formas matrimoniales propios de la cultura andina.

\section{LA FAMILIA: PARENTESCO (EL CASO LEGAL PERUANO)}

La "familia hispana" llega con su propio contenido cultural. Significa ello que impone también, dentro de otros elementos estructurales, sus propias fórmulas parentales.

El parentesco, o conexión familiar, es la relación existente entre dos o más personas en virtud de la naturaleza, de la ley o de la religión.

Natural es cuando se funda en la consanguinidad; legal cuando brota de una orden jurídica (la adopción y la afinidad); y religioso en los casos de los sacramentos del bautismo y la confirmación.

El proceso histórico de reducción numérica de la familia, del que nos habla Enneccerus, ha conllevado a que la legislación civil vigente en nuestro sistema, reconozca el parentesco consanguíneo indefinidamente en la línea recta; y sólo hasta el cuarto grado de computación civil en la línea colateral, sin perjuicio de los efectos parentales de la afinidad y de la adopción.

El parentesco religioso, figura sólo en el Código de Procedimientos Civiles, para casos concretos.

Asi entonces, en los hechos, y en materia de duración de parentesco, mientras la consanguinidad y el parentesco espiritual generan vínculos indisolubles, los creados por la adopción y la afinidad pueden desaparecer (aunque éste no sea el caso del parentesco de afinidad, por ejemplo, entre el ex-cónyuge y la ex-suegra).

A su vez, la estructura del parentesco se halla integrada por 
cuatro elementos fundamentales: el tronco, la línea, la rama y el grado.

El tronco es aquella persona reconocida como ascendiente común por las personas de cuyo parentesco se trata.

La línea que es la sucesión ordenada y completa de personas que proceden de un mismo tronco, puede ser: recta, cuando se forma con personas que descienden unas de otras y colateral, cuando se trata de personas que, sin descender unas de otras, unen líneas rectas en el ascendiente común. La línea recta ostenta una rama ascendente y otra descendente.

El grado es la distancia entre dos parientes.

Universal y jurídicamente, para los efectos de la determinación parental, son tres los sistemas que han predominado: el canónico, el germano y el romano. Sin embargo, este último es el adoptado por la legislación civil vigente, $\mathrm{y}$ tradicionalmente en el Perú.

Así el parentesco consanguíneo queda determinado por la relación existente entre las personas que descienden una de otra o de un tronco común. El grado se establece por el número de generaciones. En tanto para el parentesco consanguíneo colateral, el grado se señala subiendo de uno de los parientes al tronco común, y bajando después hasta el otro. Este parentesco produce efectos civiles sólo hasta el cuarto grado.

De otro lado, el matrimonio genera parentesco de afinidad, entre cada uno de los cónyuges, con los parientes consanguíneos del otro; y así cada cónyuge se hallará en igual línea y grado de parentesco por afinidad que el otro por consanguinidad.

La afinidad en línea recta no concluye por disolución del matrimonio que la produjo, y subsiste la afinidad en el segundo grado de la línea colateral en los casos de divorcio mientras viva el excónyuge. 


\section{CONCLUSIONES}

1. Los estudios de antropología familiar respecto a los orígenes del matrimonio, la familia y las relaciones de parentesco son confusos.

2. Empero, el factor cultural parece haber incidido para establecer tipos variados de "matrimonio", "familia" y "parentesco", según los grupos humanos.

3. Sin embargo históricamente se advierten factores comunes:

a) "necesidad de la unión marital", ( ¿unión sexual?)

b) "tendencia a las uniones grupales", ( ¿familias?)

c) "existencia de variadas formas de parentesco según las costumbres del grupo humano".

4. Para el caso del imperio de los incas se dieron todas las tendencias señaladas en la conclusión tres, naturalmente vinculadas a su propio sentimiento cultural.

5. Entre los incas, del matriarcado habrían arribado al patriarcado $\mathrm{y}$ algunas notas del parentesco andino, entre otras, habrian sido:

- importancia del ayllu y la familia;

- significación de los conceptos de jerarquía y localidad;

- en el ayllu, en estricto, se incluye la relación parental sólo hasta el cuarto grado (similitud con el parentesco colateral vigente en el Código Civil peruano actual);

- existieron reglas de impedimento matrimonial entre parientes. Los descendientes de un antepasado hasta los bisnietos no podían casarse entre sí.

De otro lado, la terminología del parentesco inca estuvo íntimamente entrelazada con los aspectos de su origen social y religioso. Así, la nobleza organizaba la filiación y el parentesco de descendencia en relación con el nuevo rey, cuando éste era elegido. Ello no tuvo sólo fines utilitarios para el rey, sino que era también necesario para todo el sistema de parentesco. 
También, se dice que, hubo vinculación directa entre el parentesco y todo el orden administrativo del sistema inca.

6. El conquistador español pretende imponer un tipo y concepto distinto de familia. Se trata de la familia monogámica, proveniente del matrimonio católico, y con parentesco familiar reducido.

El concepto se encuentra impregnado por la doctrina católica. Empero paralelamente sobreviven formas familiares típicas del ande indígena.

7. La legislación impuesta por España y dirigida a Indias traduce la concepción hispana de familia.

Ello se ha sucedido de legislación en legislación.

8. Hoy en el Perú "la familia oficial" -legal-es monogámica y estable, con parentesco consanguíneo ilimitado en línea recta y colateral válido hasta el cuarto grado; y la afinidad en línea recta produce parentesco entre cada uno de los cónyuges con los parientes consanguíneos del otro. La afinidad no acaba por la disolución del matrimonio que la produjo y subsiste en el segundo grado de la línea colateral en caso de divorcio y mientras viva el ex-cónyuge. 
Para el presente trabajo se empleó la siguiente bibliografía:

* BACHOFEN, Johann Jakob

Derecho materno

* BASADRE, Jorge

Historia del Derecho Peruano

* COBO, Bernabé

Historia del Nuevo Mundo

* COR VETTO, Anibal

Derecho Civil

* CORNEJO CHAVEZ, Héctor

Derecho Familiar Peruano

* CODIGO CIVIL PERUANO 1984

* ENGELS, Federico

El Origen de la Familia, la Propiedad y el Estado.

* FABREGA Y GRAU, Angel

Historia de los Concilios Ecuménicos

* GARCILASO DE LA VEGA, Inca

Comentarios Reales de los Incas

* HUAMAN POMA, Felipe

Nueva Crónica y Buen Gobierno

* LEVI -STRAUSS, Claude

Las Estructuras Elementales del Parentesco

* LUBBOK, John Aveburg

El Origen de la Civilización

* MAYER E. y R. BOLTON

Parentesco y Matrimonio en los Andes 
* MACLENNAN, J.F.

Estudios de Historia Antigua

* MORGAN, Lewis

La Sociedad Antigua

* VALVERDE, Emilio

El Derecho de Familia en el Código Civil Peruano

* VALEGA, José

Historia del Virreynato Peruano

* WESTERMACK, $\mathrm{R}$.

Historia del Matrimonio en la Especie Humana. 